\title{
Design of a model reference adaptive PID control algorithm for a tank system
}

\author{
Yohan Darcy Mfoumboulou \\ Departement of Electrical, Electronic, and Computer Engineering, \\ Cape Peninsula University of Technology, South Africa
}

\begin{tabular}{|c|c|}
\hline Article Info & ABSTRACT \\
\hline Article history: & This paper describes the design of an adaptive controller based on model \\
\hline Received Mar 31, 2020 & when large variations of parameters and external disturbances affect \\
\hline Revised Jun 20, 2020 & the closed-loop system. To achieve that, an innovative structure of \\
\hline Accepted Jul 6, 2020 & $\begin{array}{l}\text { the adaptive PID controller is defined, an additional PI is designed to make } \\
\text { sure that the reference model produces stable output signals and three }\end{array}$ \\
\hline Keywords: & $\begin{array}{l}\text { adaptive gains are included to guarantee stability and robustness of } \\
\text { the closed-loop system. Then, the performance of the model reference }\end{array}$ \\
\hline Adaptive & adaptive PID controller on the behaviour of the closed-loop system is \\
\hline Linearization & closed-loop systems are under various conditions. The results demonstrate \\
\hline MIT & that the MRAPIDC performs significantly better than the conventional \\
\hline MRAPIDC & PI controller. \\
\hline
\end{tabular}

Nonlinear

Parameters

Stability

This is an open access article under the CC BY-SA license.

\section{Corresponding Author:}

Yohan Darcy Mfoumboulou,

Departement of Electrical, Electronic and Computer Engineering,

Cape Peninsula University of Technology,

Bellville Campus, P.O Box 7530, South Africa.

Email: fabolous86yo@yahoo.fr

\section{INTRODUCTION}

Adaptive control of uncertain processes has become more and more important in industry. Adaptive controllers differ from ordinary ones, because their parameters are variable, and there is a mechanism for adjusting these parameters online based on signals in the system [1]. The design of an adaptive PI controller to stabilize a mass damper-spring system under parameters' uncertainties was proposed in [2]. The designed adaptive PI controller adjusts to parameters' variations, and the output of the process follows the set points, regardless of the values of the parameters. But it does not guarantee stability when external disturbances and large variations of parameters occur.

In [3], the design of a PID controller on MATLAB to maintain the level of liquid constant in a coupled-tank system (CTS) was proposed. The control parameters were found using the trial and error methodology and the results were analysed in MATLAB/Simulink environments. Proportional (P), proportional integral (PI), proportional derivative (PD) and proportional integral derivative (PID) controllers were applied on the process and their performances were compared to select the most suitable control solution. The PID controller showed superior results, but it did not guarantee stability to disturbances and variations of plant parameters.

Adaptive controllers, as opposed to conventional constant gain controllers (PID controllers), are very effective in handling situations where the variations of parameters and environmental changes are very frequent with the application of model reference adaptive control scheme in a first order system [4]. 
They noticed that the newer adaptive control schemes could not cope with drastic changes in loads, inertias and forces, unpredictable and sudden faults, or frequent, or unforeseen disturbances. Most conventional PID controllers with constant gain were also unable to cope with these problems. For this reason, the authors developed a control technique to solve these problems and added an adaptation gain to show the effects on the system performance.

An adaptive control algorithm of a water tank model was simulated in [5]. It was concluded that, compared to the one degree of freedom (1DOF) algorithm, the two degrees of freedom algorithm (2DOF) reduced the control input demands, which was important from the practical point of view. But the $2 \mathrm{DOF}$ had slower output response compared to the $1 \mathrm{DOF}$.

A robust optimal adaptive control strategy was developed in [6] to deal with tracking problem of a quadrotor unmanned aerial vehicle (UAV). The controller has a prominent ability to stabilize nonlinear dynamic system of quadrotor, force the states to follow desired reference signals, and find optimal solution for the tracking problem without control input saturation. The performance analysis of a conventional PID controller and a MRAC was done in [7]. Cylindrical tank interacting and noninteracting systems were selected as processes to be controlled. The results showed that the MRAC has better overshoot, settling time and set-point tracking performance than the conventional PID controller.

The development of direct and indirect adaptive control methods to control the power in a TRIGA MARK II reactor was proposed in [8]. The analysis showed that the adaptive algorithm offers overall better results than the feedback control algorithm. The adaptive algorithm reduced the settling time up to $25 \%$ of the nominal settling time.

A model reference adaptive controller without integral (MRACWI) parameter for position control of a DC Motor was designed in [9]. The controller produced better performance in terms of settling time, percentage overshoot and mean square error as compared with PID controller, standard MRAC and MRAC with a sigma modification. A drawback of this algorithm is that its performance to variations of parameters and external disturbances is unknown.

A comparison of the time specification performance between a conventional PID controller and a modern sliding mode controller (SMC) for a nonlinear inverted pendulum system was done in [10]. The performances of both control strategies were assessed to see which one had better handling of pendulum's angle and cart's position. The overall results of the analysis showed that the sliding mode controller had faster rising time, better settling time and a much better percentage of overshoot compared to the conventional PID. Both controllers did not have any steady state errors. Since the inverted pendulum is a highly nonlinear system, this research showed two drawbacks. The authors did not investigate the performance of the controllers when external disturbances and variations of parameters occur. These studies would have made the investigation more realistic.

Advanced PID are also used in the medical sector, [11] proposed a fractional order PID controller and an integer order PID controller for supressing epileptic activities. Both controllers showed great results to stabilize the patient, but the fractional order PID controller is more suitable for implementation in FPGA because it uses less flip-flops. Unfortunately, the study did not take in consideration sudden abnormal activities of the brain cells to evaluate the time response taken by the controller to stabilize the patient. This study is crucial to bring the patient back to a good health condition in the shortest time possible.

In [12], a novel data-driven sigmoid-based PI controller was designed to track the angular velocity of dc motor powered by a dc/dc buck converter. The results of the investigations showed that the data-driven sigmoid-based PI, which is tuned using global simultaneous perturbation stochastic approximation, yields a better angular velocity tracking as compared to conventional PI and PI-Fuzzy. A drawback of this study is that, the performance of the sigmoid-based controller was not evaluated for disturbance rejection.

In [13], the performance of the fractional order proportional-integral-derivative (FOPID) controllers designed by using artificial bee colony $(\mathrm{ABC})$ for fractional orders systems is compared to conventional PID controller optimized by the ABC colony algorithm. The results of the simulations showed that the FOPID controllers had significantly better performance compared to the conventional PID controllers. Unfortunately, there was no study made to evaluate the performance of the controller when disturbances occur.

An adaptive safe experimentation dynamics (ASED) for data driven neuroendocrine-PID control of MIMO Systems was designed in [14]. The performance of the ASED based method was compared to the standard safe experimentation dynamics (SED) and simultaneous perturbation stochastic approximation (SPSA) based methods. The results of the simulations showed that the ASED and SED based methods have successfully solved the unstable convergence issue in the existing neuroendocrine-PID based standard SPSA. Moreover, the presented ASED based algorithm outperforms the SED and the SPSA based methods in the perspective of the control performance accuracy in terms of lower objective function, total norm error and total norm input. A drawback of this research is that, the authors did not perform plant's parameters changes to see the influence of the adaptive gain of the ASED controller. The research gap and merit of the adaptive 
PID controller developed in this paper compared to the other advanced PID controllers reviewed is that, the proposed controller can stabilize the closed-loop system when variations of parameters and sudden random disturbances occur simultaneously. None of the reviewed papers explored this scenario.

The main contribution of this paper is that it presents the design of a model reference adaptive PID controller (MRAPIDC) based on the MIT approach to stabilize and optimize the linearized model of the twotank liquid level process affected by sudden changes of parameters and input disturbance. Then, a reference model is developed based on control theory, and a PI regulator is designed on MATLAB to control the reference model. The designed PI controller is a novel idea to add stability to the output signals of the reference model, hence making the adaptive algorithm more robust. Another novelty of this research is the inclusion of three new adaptive gains in the final structure of the MRAPIDC to make the closed-loop system robust when large variations of parameters and sudden external disturbances occur simultaneously. The controller keeps the percentage of overshoot of the closed-loop system below $10 \%$ and its recovery time to sudden variations of parameters is lower than 5 seconds, which is a huge advantage compared to the other adaptive controllers reviewed. Another advantage of this adaptive algorithm is that real-time tuning of the three adaptive gains can be done to improve the performance of the closed-loop system. Furthermore, the performance of the MRAPIDC is compared to a classic PI controller designed on MATLAB for the linearized model of the two-tank system. The adaptive control algorithms, PI control algorithm and the models of the closed-loop systems are simulated in MATLAB/Simulink.

The outline of this paper is as follows: the modelling and simulation of the process is proposed in section 2. Section 3 discusses the design of a MRAPIDC based on model reference theory. The simulation results are shown in section 4 . Section 5 draws the conclusion.

\section{MODELING AND SIMULATION OF THE TWO-TANK SYSTEM}

In this paper, a two-tank liquid level system is selected as a plant to be controlled, because it is a nonlinear inherently unstable system. The system is made of two-tank mounted above a reservoir, which has the function of a storage element for liquid. The system has an independent pump to pump liquid from the reservoir to the tanks. The two-tanks are interacting, which means that the liquid moves from one tank to the other. When two tanks are state dependent, the interaction of liquid between the tanks exhibits a nonlinear behaviour [15]. The simplified block diagram of the process is shown in Figure 1.

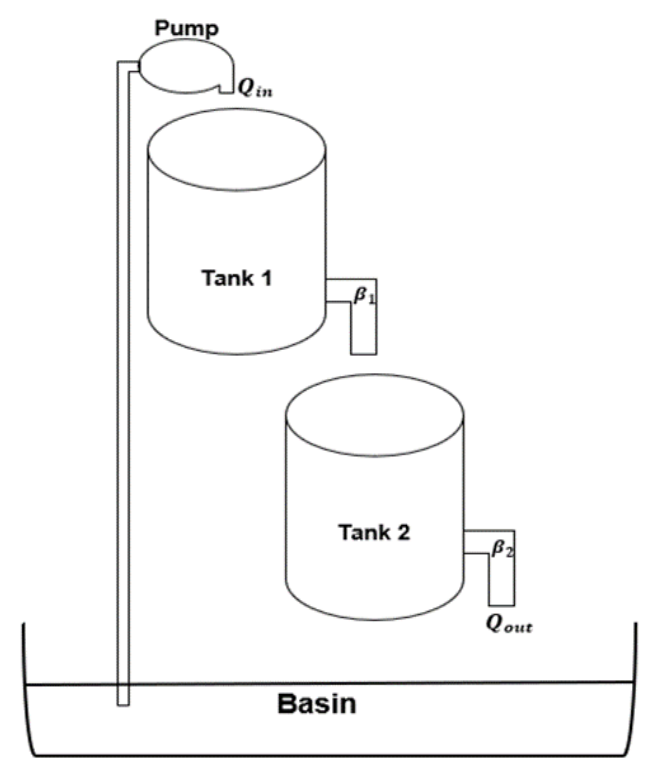

Figure 1. Block diagram of a two-tank liquid level process

The parameters of the two-tank liquid level system are the following:

$h_{1} \quad=$ level of liquid in tank 1 in $\mathrm{cm}$

$h_{2} \quad=$ level of liquid in tank 2 in $\mathrm{cm}$

$A_{1}=$ cross sectional area of tank 1 in $\mathrm{cm}^{2}$

Int J Elec \& Comp Eng, Vol. 11, No. 1, February 2021 : 300 - 318 
$A_{2}=$ cross sectional area of tank 2 in $\mathrm{cm}^{2}$

$a_{1}=$ cross sectional area of the outlet pipe in tank 1 in $\mathrm{cm}^{2}$

$a_{2}=$ cross sectional area of the outlet pipe in tank 2 in $\mathrm{cm}^{2}$

$Q_{\text {in }} \quad=$ flow rate of liquid into tank $1 \mathrm{~cm}^{2} / \mathrm{sec}$

$Q_{\text {out }}=$ flow rate of liquid out of tank $2 \mathrm{~cm}^{2} / \mathrm{sec}$

$\beta_{1} \quad=$ valve ratio of outlet pipe of tank 1

$\beta_{2} \quad=$ valve ratio of the outlet pipe of tank 2

$g \quad=$ gravitational force

$k \quad=$ pump gain

$u(t) \quad=$ input voltage to the pump

The nonlinear equations of the two-tank liquid system model can be derived by applying the Bernoulli's law of conservation of mass [15]:

$$
A \frac{d h}{d t}=Q_{\text {in }}-Q_{o u t}
$$

The nonlinear dynamic equations derived from tank 1 are:

$$
\begin{aligned}
& A_{1} \frac{d h_{1}(t)}{d t}=Q_{i n}-\beta_{1} a_{1} \sqrt{2 g h_{1}(t)} \\
& u(t)=Q_{\text {in }} \text { (input flow) } \\
& \frac{d h_{1}(t)}{d t}=\frac{1}{A_{1}}\left[k u(t)-\beta_{1} a_{1} \sqrt{2 g h_{1}(t)}\right.
\end{aligned}
$$

The dynamic equations derived from tank 2 are:

$$
\begin{aligned}
& A_{2} \frac{d h_{2}(t)}{d t}=\beta_{1} a_{1} \sqrt{2 g h_{1}(t)}-\beta_{2} a_{2} \sqrt{2 g h_{2}(t)} \\
& \frac{d h_{2}(t)}{d t}=\frac{\beta_{1} a_{1}}{A_{2}} \sqrt{2 g h_{1}(t)}-\frac{\beta_{2} a_{2}}{A_{2}} \sqrt{2 g h_{2}(t)}
\end{aligned}
$$

At equilibrium for a continuous liquid level set-point, the derivative of the liquid levels in the tanks must be zero $\left(\dot{h}_{1}=\dot{h}_{2}=0\right)$. In the scenario when: $h_{1}=h_{2}$; the system is state decoupled. Therefore, to satisfy the conditions of the simulation of the liquid level system: $h_{1}>h_{2}$, the level of liquid in tank 1 must be bigger than this of tank 2 .

The state space representation of the nonlinear system is the following:

$$
\begin{aligned}
& {\left[\begin{array}{l}
\frac{d h_{1}(t)}{d t} \\
\frac{d h_{2}(t)}{d t}
\end{array}\right]=\left[\begin{array}{c}
\frac{1}{A_{1}}\left[k u(t)-\beta_{1} a_{1} \sqrt{h_{1}(t)}\right] \\
\frac{1}{A_{2}}\left[\beta_{1} a_{1} \sqrt{2 g h_{1}(t)}-\beta_{2} a_{2} \sqrt{2 g h_{2}(t)}\right]
\end{array}\right]} \\
& y=C\left[\begin{array}{ll}
h_{1} & h_{2}
\end{array}\right]^{T}=\left[\begin{array}{ll}
0 & 1
\end{array}\right]\left[\begin{array}{ll}
h_{1} & h_{2}
\end{array}\right]^{T}
\end{aligned}
$$

Then:

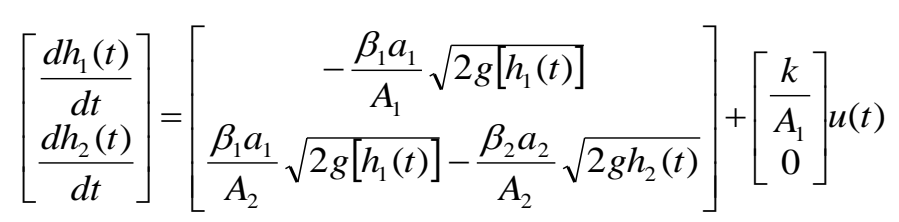




$$
y=C\left[\begin{array}{ll}
h_{1} & h_{2}
\end{array}\right]^{T}=\left[\begin{array}{ll}
0 & 1
\end{array}\right]\left[\begin{array}{ll}
h_{1} & h_{2}
\end{array}\right]^{T}
$$

The parameters of the two-tank process are given in Table 1.

Table 1. Values of the parameters of the process

\begin{tabular}{ll}
\hline Parameters & Values \\
\hline$A_{1}, A_{2}\left(\mathrm{~cm}^{2}\right)$ & 75 \\
$a_{2}, a_{1}\left(\mathrm{~cm}^{2}\right)$ & 1.5 \\
$\beta_{1}$ & 1.5315195 \\
$\beta_{2}$ & 0.6820043 \\
$g\left(\mathrm{~cm} / \mathrm{sec}^{2}\right)$ & 981 \\
$k$ & 30.0024 \\
\hline
\end{tabular}

The next section is to derive a linearized model of the nonlinear tank process to find an accurate equivalence of both models.

\subsection{Linearization of the nonlinear model of the two-tank process}

The linearization of the two-tank liquid system is performed around its operating points, and to achieve that, only the linear terms of the Taylor series expansion of the nonlinear model are considered. In (7) and (8) are considered to linearize the nonlinear model of the system.

Let define the state variables of the system:

$h_{1}=x_{1}=$ level of liquid in tank 1.

$h_{2}=x_{2}=$ level of liquid in tank 2 .

By substituting $h_{1}$ and $h_{2}$, by $x_{1}$ and $x_{2}$ in (7) and (8), it is obtained:

$$
\begin{aligned}
& {\left[\begin{array}{l}
\dot{x}_{1} \\
\dot{x}_{2}
\end{array}\right]=\left[\begin{array}{c}
-\frac{\beta_{1} a_{1}}{A_{1}} \sqrt{2 g x_{1}} \\
\frac{\beta_{1} a_{1}}{A_{2}} \sqrt{2 g x_{1}}-\frac{\beta_{2} a_{2}}{A_{2}} \sqrt{2 g x_{2}}
\end{array}\right]+\left[\begin{array}{c}
\frac{k}{A_{1}} \\
0
\end{array}\right] u} \\
& y=C\left[\begin{array}{ll}
x_{1} & x_{2}
\end{array}\right]^{T}=\left[\begin{array}{ll}
0 & 1
\end{array}\right]\left[\begin{array}{ll}
x_{1} & x_{2}
\end{array}\right]^{T}
\end{aligned}
$$

The (9) and (10) can be expressed by the standard nonlinear model:

$$
\begin{aligned}
& \dot{x}=f(x)+g(x) u=\left[\begin{array}{l}
f_{1}(x) \\
f_{2}(x)
\end{array}\right]+\left[\begin{array}{l}
g_{1}(x) \\
g_{2}(x)
\end{array}\right] u \\
& y=\bar{o}(x)
\end{aligned}
$$

where: $f(x), g(x)$ and $\bar{o}(x)$ are the nonlinear vector functions of the state vector.

The linearization of the nonlinear model is performed according to Taylor series method. The linearized model is derived based of the nonlinear functions $f_{1}, f_{2}, g_{1}$ and $g_{2}$. For the case of the twotank system, the nonlinear functions are:

$$
\begin{aligned}
& f_{1}=-\frac{\beta_{1} a_{1}}{A_{1}} \sqrt{2 g x_{1}}, g_{1}=\frac{k}{A_{1}} u \\
& f_{2}=\frac{\beta_{1} a_{1}}{A_{2}} \sqrt{2 g x_{1}}-\frac{\beta_{2} a_{2}}{A_{2}} \sqrt{2 g x_{2}}, g_{2}=0
\end{aligned}
$$

- The derivatives of the first function $f_{1}$ according to the two states $x_{1}, x_{2}$ and the control input $u$ :

$$
\frac{\partial}{\partial x_{1}}\left(f_{1}\right)=\frac{\partial}{\partial x_{1}}\left[-\frac{\beta_{1} a_{1}}{A_{1}} \sqrt{2 g x_{1}}\right]
$$




$$
\frac{\partial}{\partial x_{1}}\left(f_{1}\right)=-\frac{g \beta_{1} a_{1}}{A_{1} \sqrt{2 g x_{1}}}
$$

Then:

$$
\begin{aligned}
& \frac{\partial}{\partial x_{2}}\left(f_{1}\right)=\frac{\partial}{\partial x_{2}}\left[-\frac{\beta_{1} a_{1}}{A_{1}} \sqrt{2 g x_{1}}\right] \\
& \frac{\partial}{\partial x_{2}}\left(f_{1}\right)=0
\end{aligned}
$$

The derivative according to $u$ is:

$$
\frac{\partial}{\partial u}\left(f_{1}\right)=0
$$

- Derivatives of the second function $f_{2}$ according to the two states are:

$$
\begin{aligned}
\frac{\partial}{\partial x_{1}}\left(f_{2}\right) & =\frac{\partial}{\partial x_{1}}\left[\frac{\beta_{1} a_{1}}{A_{2}} \sqrt{2 g x_{1}}\right] \\
\frac{\partial}{\partial x_{1}}\left(f_{2}\right) & =\frac{g \beta_{1} a_{1}}{A_{2} \sqrt{2 g x_{1}}} \\
\frac{\partial}{\partial x_{2}}\left(f_{2}\right) & =\frac{\partial}{\partial x_{2}}\left[\frac{\beta_{1} a_{1}}{A_{2}} \sqrt{2 g x_{1}}-\frac{\beta_{2} a_{2}}{A_{2}} \sqrt{2 g x_{2}}\right] \\
\frac{\partial}{\partial x_{2}}\left(f_{2}\right) & =-\frac{g \beta_{2} a_{2}}{A_{2} \sqrt{2 g x_{2}}}
\end{aligned}
$$

The terms of the control matrix B can also be found with the same procedure:

- Derivative of $g_{1}$ per the two states:

$$
\begin{aligned}
& \frac{\partial}{\partial x_{1}}\left(g_{1}\right)=\frac{\partial}{\partial x_{1}}\left[\frac{k}{A_{1}}\right] \\
& \frac{\partial}{\partial x_{1}}\left(g_{1}\right)=0
\end{aligned}
$$

For $x_{2}$ :

$$
\begin{aligned}
& \frac{\partial}{\partial x_{2}}\left(g_{1}\right)=\frac{\partial}{\partial x_{2}}\left[\frac{k}{A_{1}}\right] \\
& \frac{\partial}{\partial x_{2}}\left(g_{1}\right)=0
\end{aligned}
$$

- Derivative of $g_{2}$ according to the two states:

$$
\begin{aligned}
& \frac{\partial}{\partial x_{1}}\left(g_{2}\right)=0 \\
& \frac{\partial}{\partial x_{2}}\left(g_{2}\right)=0
\end{aligned}
$$

After all the linearized expressions of the system are done, the linearized state space representation of the two-tank process is:

$$
\begin{aligned}
& {\left[\begin{array}{l}
\dot{x}_{1} \\
\dot{x}_{2}
\end{array}\right]=\left[\begin{array}{cc}
-\frac{g \beta_{1} a_{1}}{A_{1} \sqrt{2 g x_{1}}} & 0 \\
\frac{g \beta_{1} a_{1}}{A_{2} \sqrt{2 g x_{1}}} & \left(-\frac{g \beta_{2} a_{2}}{A_{2} \sqrt{2 g x_{2}}}\right)
\end{array}\right]\left[\begin{array}{c}
x_{1} \\
x_{2}
\end{array}\right]+\left[\begin{array}{c}
\frac{k}{A_{1}} \\
0
\end{array}\right] u} \\
& y=\left[\begin{array}{ll}
0 & 1
\end{array}\right]\left[\begin{array}{l}
x_{1} \\
x_{2}
\end{array}\right]
\end{aligned}
$$


where the coefficients of the matrices defined in (24) are calculated for the equilibrium values of the state variables given by (6) and (7). At equilibrium for continuous liquid level set-point, the derivative must be zero $\left(\dot{h_{1}}=\dot{h_{2}}=0\right)$. In the scenario when: $h_{1}=h_{2}$, the system is state decoupled. Therefore, to satisfy the conditions of the simulation of the liquid level system: $h_{1}>h_{2}$. The model defined by (6) and (7) will be used to develop the adaptive control algorithm.

\section{DESIGN OF A MODEL-REFERENCE ADAPTIVE PID-CONTROLLER}

The Massachusetts Institute of Technology (MIT) rule is a gradient rule. It was derived at MIT in its instrumentation laboratory, hence its name. The MIT rule is the original approach to model reference adaptive control (MRAC) $[15,16]$. To give a representation of the MIT rule, let consider $\theta$ as an adjustable parameter of a controller. The desired closed-loop response of the output is $y_{m}$; and the error between the output $y$ of the closed-loop system and the output $y_{m}$ of the refrerence model is $\varepsilon$. In the paper, the desired output $y_{m}$ is proposed to be determined by a reference model output. To define the MIT rule, let consider the following loss function [17]:

$$
J(\theta)=\frac{1}{2} \varepsilon^{2}
$$

It is necessary to determine at every moment of time the parameters of the controller in such a way that the function $J(\theta)$ is minimized.

The MIT fundamental approach consists of adjusting the parameters of the closed-loop system such that the loss function described in (25) is minimized. To minimize the function $J(\theta)$, a realistic approach would be to change the parameters of the system in the direction of the negative gradient of $J$ :

$$
\frac{d \theta}{d t}=-\gamma \frac{\partial J}{\partial \theta}=-\gamma \varepsilon\left(\frac{\partial \varepsilon}{\partial \theta}\right)
$$

where: $\gamma$ is an adaptation gain; and $\left(\frac{\partial \varepsilon}{\partial \theta}\right)$ is the sensitivity derivative function of the system towards its timevarying parameters. $\theta$ represents in this case, the time varying parameters of the controller.

In (26) is the MIT rule. The sensitivity derivative expresses how the adjustable parameters influence the error. In general, it is assumed that the parameter changes are slower than the other variables of the system. Hence, the sensitivity derivative $\left(\frac{\partial \varepsilon}{\partial \theta}\right)$ can be evaluated by assuming that the adjustable parameter $\theta$ is constant. To summarize, the following steps can be used to design an adaptive controller based on the MIT rule:

- Define the coefficients of the transfer function of a plant with unknown parameters.

- Choose a reference model.

- Choose a control algorithm to achieve perfect model tracking.

- Define the error of the closed-loop system.

- Derive the expressions of the control parameters.

- Apply the negative gradient of $J$ to find the updating parameters.

\subsection{Determination of the transfer function coefficients for the linearized model}

The state space representation of the tank process is represented as given in (24):

$$
\begin{aligned}
& {\left[\begin{array}{l}
\dot{x}_{1} \\
\dot{x}_{2}
\end{array}\right]=\left[\begin{array}{cc}
-\frac{g \beta_{1} a_{1}}{A_{1} \sqrt{2 g x_{1}}} & 0 \\
\frac{g \beta_{1} a_{1}}{A_{2} \sqrt{2 g x_{1}}} & \left(-\frac{g \beta_{2} a_{2}}{A_{2} \sqrt{2 g x_{2}}}\right)
\end{array}\right]\left[\begin{array}{l}
x_{1} \\
x_{2}
\end{array}\right]+\left[\begin{array}{c}
\frac{k}{A_{1}} \\
0
\end{array}\right] u} \\
& y=\left[\begin{array}{ll}
0 & 1
\end{array}\right]\left[\begin{array}{l}
x_{1} \\
x_{2}
\end{array}\right]
\end{aligned}
$$

To make mathematical calculations much simpler, (24) is rewritten as:

$$
\begin{aligned}
& {\left[\begin{array}{l}
\dot{x}_{1} \\
\dot{x}_{2}
\end{array}\right]=\left[\begin{array}{cc}
T_{11} & 0 \\
T_{21} & T_{22}
\end{array}\right]\left[\begin{array}{l}
x_{1} \\
x_{2}
\end{array}\right]+\left[\begin{array}{c}
\frac{k}{A_{1}} \\
0
\end{array}\right] u} \\
& y=\left[\begin{array}{ll}
0 & 1
\end{array}\right]\left[\begin{array}{l}
x_{1} \\
x_{2}
\end{array}\right]
\end{aligned}
$$


where:

$$
T_{11}=-\frac{g \beta_{1} a_{1}}{A_{1} \sqrt{2 g x_{1}}} ; T_{21}=\frac{g \beta_{1} a_{1}}{A_{2} \sqrt{2 g x_{1}}} ; T_{22}=-\frac{g \beta_{2} a_{2}}{A_{2} \sqrt{2 g x_{2}}}
$$

The matrices of the state space model can be represented as:

$$
A=\left[\begin{array}{cc}
T_{11} & 0 \\
T_{21} & T_{22}
\end{array}\right] ; B=\left[\begin{array}{c}
\frac{k}{A_{1}} \\
0
\end{array}\right] ; C=\left[\begin{array}{ll}
0 & 1
\end{array}\right] ; \text { and } D=0
$$

To transform the state space model of the linearized system to transfer function, the following formula is applied [18]:

$$
T f(s)=\frac{N(s)}{P(s)}=C(s I-A)^{-1} B+D
$$

where $I$ is the identity matrix, and:

$$
S I=\left[\begin{array}{ll}
S & 0 \\
0 & S
\end{array}\right]
$$

The calculation of the transfer function of the linearized model is the following:

$$
\begin{aligned}
& T f(s)=\left[\begin{array}{ll}
0 & 1
\end{array}\right] \times\left(\left[\begin{array}{ll}
s & 0 \\
0 & s
\end{array}\right]-\left[\begin{array}{cc}
T_{11} & 0 \\
T_{21} & T_{22}
\end{array}\right]\right)^{-1} \times\left[\begin{array}{c}
k \\
A_{1} \\
0
\end{array}\right] \\
& T f(s)=\left[\begin{array}{ll}
0 & 1
\end{array}\right] \times\left(\left[\begin{array}{cc}
\left(s-T_{11}\right) & 0 \\
-T_{21} & \left(s-T_{22}\right)
\end{array}\right]\right)^{-1} \times\left[\begin{array}{c}
\frac{k}{A_{1}} \\
0
\end{array}\right]
\end{aligned}
$$

Then:

$$
\begin{aligned}
& T f(s)=\left[\begin{array}{ll}
0 & 1
\end{array}\right] \times\left[\begin{array}{cc}
\operatorname{adj}\left[\begin{array}{cc}
\left(s-T_{11}\right) & 0 \\
-T_{21} & \left(s-T_{22}\right.
\end{array}\right] \\
\left|\begin{array}{cc}
\left(s-T_{11}\right) & 0 \\
-T_{21} & \left(s-T_{22}\right)
\end{array}\right|
\end{array}\right] \times\left[\begin{array}{c}
\frac{k}{A_{1}} \\
0
\end{array}\right] \\
& T f(s)=\left[\begin{array}{ll}
0 & 1
\end{array}\right] \times\left[\frac{\left[\begin{array}{cc}
\left(s-T_{22}\right) & 0 \\
T_{21} & \left(s-T_{11}\right)
\end{array}\right]}{\left[s^{2}+\left(-T_{11}-T_{22}\right) s+T_{11} T_{22}\right]}\right] \times\left[\begin{array}{c}
\frac{k}{A_{1}} \\
0
\end{array}\right] \\
& T f(s)=\left[\begin{array}{ll}
0 & 1
\end{array}\right] \times\left[\frac{\left[\begin{array}{c}
\left(s-T_{22}\right) \times\left(\frac{k}{A_{1}}\right) \\
T_{21}\left(\frac{k}{A_{1}}\right)
\end{array}\right]}{\left[s^{2}+\left(-T_{11}-T_{22}\right) s+T_{11} T_{22}\right]}\right] \\
& T f(s)=\left[\frac{(o) \times\left(s-T_{22}\right) \times\left(\frac{k}{A_{1}}\right)+(1) \times T_{21}\left(\frac{k}{A_{1}}\right)}{\left[s^{2}+\left(-T_{11}-T_{22}\right) s+T_{11} T_{22}\right]}\right]
\end{aligned}
$$

The final representation of the transfer function of the linearized model is: 


$$
T f(s)=\frac{T_{21}\left(\frac{k}{A_{1}}\right)}{s^{2}+\left(-T_{11}-T_{22}\right) s+T_{11} T_{22}}
$$

The design of the model reference adaptive PID controller to stabilize the developed linearized model is described in the next section.

\subsection{Procedure to design the model-reference adaptive PID-controller (MRAPIDC) for the linearized} model of the two-tank liquid level system

To make the derivation of the adaptive PID controller much simpler mathematically, the final expression of the transfer function of the linearized model is simplified as:

$$
G(s)=\frac{a_{3}}{a_{0} s^{2}+a_{1} s+a_{2}}
$$

where:

$$
T f(s)=G(s) ; a_{0}=1 ; a_{1}=\left(-T_{11}-T_{22}\right) ; a_{2}=T_{11} T_{22} \quad a_{3}=T_{21}\left(\frac{k}{A_{1}}\right)
$$

The parameters of the new transfer function are defined as:

$$
a_{1}=\theta_{1} l_{1}, a_{2}=\theta_{2} l_{2} \text { and } a_{3}=\theta_{3} l_{3} .
$$

$\theta_{1}, \theta_{2}$ and $\theta_{3}$ are the varying parameters; and $l_{1}, l_{2}$ and $l_{3}$ are the fixed parameters of the process.

\subsubsection{Design of the desired linear reference model}

The linearized model of the tank system is of a second order. Therefore, the linear reference model can be designed as a typical second order transfer function as follows:

From the design specifications, the values of the dominant poles can be obtained as follows:

$$
R(s)=\frac{\omega_{n}^{2}}{s^{2}+2 \omega_{n} \zeta s+\omega_{n}^{2}}=\frac{Y_{m}(s)}{R_{i n}(s)}
$$

where: $R(s)$ is the transfer function of the reference model, $Y_{m}$ is the output of the reference model and $R_{i n}$ is its input.

Then the output of the reference model is:

$$
Y_{m}(s)=\frac{\omega_{n}^{2}}{s^{2}+2 \zeta \omega_{n} s+\omega_{n}^{2}} R_{i n}(s)
$$

To guarantee the stability of the closed-loop system, the reference model must meet the following design characteristics:

- Percentage of Overshoot (PO): $8 \%$

- Settling time: 2 seconds

- T ime delay: 0 second

- Steady state error: 0

From the design specifications, the values of the dominant poles can be obtained as follows [19, 20]:

- The damping ratio for a percentage of overshoot $(\mathrm{PO})$ of $8 \%$ is:

$$
\begin{aligned}
& \zeta=\sqrt{\frac{\left(\ln \frac{P O}{100 \%}\right)^{2}}{\pi^{2}+\left(\ln \frac{P O}{100 \%}\right)^{2}}} \\
& \zeta=\sqrt{\frac{\ln (0.08)^{2}}{\pi^{2}+\ln (0.08)^{2}}}=0.63
\end{aligned}
$$


The phase angle of the dominant poles is:

$$
\begin{aligned}
& \varphi=\cos ^{-1}(\zeta)=\cos ^{-1}(0.63) \\
& \varphi=50.95^{\circ}
\end{aligned}
$$

The values of the real and imaginary poles are calculated as follow:

$$
\begin{aligned}
& \operatorname{Re} \operatorname{al}(s)=-\frac{4}{T_{s}}=-\frac{4}{2 s}=-2 \\
& \operatorname{Im} \operatorname{ag}(s)=\operatorname{Re} \operatorname{al}(s) \times \tan (\varphi)=-2 \tan \left(50.95^{\circ}\right) \\
& \operatorname{Im} \operatorname{ag}(s)=-2.46 i
\end{aligned}
$$

The value of the first dominant pole is:

$$
\begin{aligned}
& P_{1}=\operatorname{Real}(s)+\operatorname{Imag}(s) \\
& P_{1}=-2-2.46 i
\end{aligned}
$$

The natural frequency of the reference model is found based on the polynomial of the dominant poles:

$$
\begin{aligned}
& P_{\text {dom }}(s)=(s+2+2.46 i)(s+2-2.46 i) \\
& P_{d o m}(s)=s^{2}+4 s+10.0516 \\
& \omega_{n}=\sqrt{10.0516}=3.17 \mathrm{rad} / \mathrm{s}
\end{aligned}
$$

The desired closed-loop transfer function of the reference model is:

$$
R(s)=\frac{10.0516}{s^{2}+4 s+10.0516}
$$

To ensure stability and robustness of the closed-loop system when large variations of parameters occur, a proportional integral (PI) controller is designed on MATLAB for the reference model R(s) using the programming command line pid $\left(K_{p}, K_{i}\right)$ [21,22]. The parameters $K_{p}$ and $K_{i}$ are tunned to find their optimal values. This additional PI has also the ability to guarantee stability when sudden external disturbances affecting the two-tank process occur. The parameters of the PI controller are:

$$
K_{p}=0.001 \text { and } K_{i}=4
$$

The transfer function of the PI controller is the following:

$$
G_{P I}(s)=\frac{K_{p} s+K_{i}}{s}=\frac{0.001 s+4}{s}
$$

\subsubsection{Selection of the control algorithm to achieve perfect model tracking}

To achieve perfect model tracking, the following proportional integral derivative (PID) control algorithm is selected for the process as:

$$
u(t)=k_{p} e(t)+k_{i} \int e(t) d t-k_{d} \dot{y}(t)
$$

where: $k_{p}$ is the proportional gain; $k_{i}$ is the integral gain; $k_{d}$ is the derivative gain; $y$ is the plant output; and $e(t)=r_{i n}(t)-y(t)$, with $r_{i n}(t)$ as the input of the reference model.

The representation of the PID controller in Laplace domain is:

$$
U(s)=K_{p} E(s)+\frac{1}{s} K_{i} E(s)-s K_{d} Y(s)
$$


The output $Y(s)$ of the two-tank liquid level process can be found as follows:

$$
Y(s)=G(s) U(s)
$$

The substitution of (30) into (31) gives:

$$
Y(s)=G(s)\left[K_{p} E(s)+\frac{1}{s} K_{i} E(s)-s K_{d} Y(s)\right]
$$

The closed-loop system is:

$$
Y(s)=G(s) E(s)\left[K_{p}+\frac{1}{s} K_{i}\right]-s K_{d} Y(s) G(s)
$$

It is known that:

$$
E(s)=R_{\text {in }}(s)-Y(s)
$$

Then $E(s)$ is substituted in (32):

$$
\begin{aligned}
& Y(s)=G(s)\left[R_{\text {in }}(s)-Y(s)\right]\left[K_{p}+\frac{1}{s} K_{i}\right]-s K_{d} Y(s) G(s) \\
& Y(s)+\left[K_{p}+\frac{1}{s} K_{i}+s K_{d}\right] G(s) Y(s)=G(s) R_{\text {in }}(s)\left[K_{p}+\frac{1}{s} K_{i}\right] \\
& Y(s)\left[1+\left(K_{p}+\frac{1}{s} K_{i}+s K_{d}\right) G(s)\right]=G(s) R_{\text {in }}(s)\left[K_{p}+\frac{1}{s} K_{i}\right] \\
& Y(s)=\frac{\left[s K_{p} G(s)+K_{i} G(s)\right] R_{\text {in }}(s)}{s^{2} K_{d} G(s)+\left(1+K_{p} G(s)\right) s+K_{i} G(s)}
\end{aligned}
$$

The PID coefficients are not known. It is necessary to determine them in such a way that the PID controller has adaptive behaviour towards the parameters variations of the process to be controlled. The design of the PID controller is further done in the time domain. In the time domain, (33) can be written as given in [2-23], because of the following:

- The model parameters vary at every moment of time.

- The adaptive controller must change its parameters also at every moment of time.

To convert (28) to the time domain, a differential operator is introduced [23]. In (36) represents the cost function in (25), and $\theta=k_{p}, k_{i}, k_{d}$.

Following [2-23], the representation of (33) in the time domain is:

$$
y(t)=\frac{\left\lfloor p k_{p} g(t)+k_{i} g(t)\right\rfloor r_{i n}(t)}{p^{2} k_{d} g(t)+\left(1+k_{p} g(t)\right) p+k_{i} g(t)}
$$

where: $p$ is a differential operator.

\subsubsection{Determination of the error between the plant states and the reference model states}

The tracking error of the closed-loop system and the reference model is [24, 25]:

$$
\varepsilon(t)=y(t)-y_{m}(t)
$$

Substituting (28) and (34) in (35) gives:

$$
\varepsilon(t)=\frac{\left[p k_{p} g(t)+k_{i} g(t)\right] r_{i n}(t)}{p^{2} k_{d} g(t)+\left(1+k_{p} g(t)\right) p+k_{i} g(t)}-\frac{\omega_{n}^{2}}{p^{2}+2 \zeta \omega_{n} p+\omega_{n}^{2}} r_{i n}(t)
$$


$\varepsilon(\mathrm{t})$ is the error between the transition behaviour of the closed-loop system and the reference model. The criterion for optimization in (25) is given by (36).

\subsubsection{Derivations of the expressions of the control parameters}

The expressions of the sensitivity functions of the closed-loop system error towards the controller parameters are derived by differentiating (36). These expressions are defined as $\frac{\partial \varepsilon(t)}{\partial k_{p}}, \frac{\partial \varepsilon(t)}{\partial k_{i}}$, and $\frac{\partial \varepsilon(t)}{\partial k_{d}}$. They are derived as follows:

$$
\begin{aligned}
& \text { For } \frac{\partial \varepsilon(t)}{\partial k_{p}} \text { : } \\
& \frac{\partial \varepsilon(t)}{\partial k_{p}}=\left[\frac{g(t) e(t) p}{k_{d} g(t) p^{2}+\left(1+k_{p} g(t)\right) p+k_{i} g(t)}\right]
\end{aligned}
$$

For $\frac{\partial \varepsilon(t)}{\partial k_{i}}$ :

$$
\frac{\partial \varepsilon(t)}{\partial k_{i}}=\left[\frac{g(t) e(t)}{k_{d} g(t) p^{2}+\left(1+k_{p} g(t)\right) p+k_{i} g(t)}\right]
$$

For $\frac{\partial \varepsilon(t)}{\partial k_{d}}$ :

$$
\left.\frac{\partial \varepsilon(t)}{\partial k_{d}}=\left[-\frac{y(t) g(t) p^{2}}{\left[k_{d} g(t) p^{2}+\left(1+k_{p} g(t)\right) p+k_{i} g(t)\right.}\right]\right]
$$

To make sure that there is a perfect tracking error, let assume that, the time behaviour of the process is equal to the time behaviour of the reference model, as follows:

$$
\left[\left[k_{d} g(t) p^{2}+\left(1+k_{p} g(t)\right) p+k_{i} g(t)\right]\right]=\frac{\omega_{n}^{2}}{p^{2}+2 \zeta \omega_{n}^{2} p+\omega_{n}^{2}}
$$

The gradient method described in (26) is applied to find the expressions of the control parameters:

$$
\begin{aligned}
& \dot{k}_{p}=\left(-\gamma_{p}\right) \varepsilon(t)\left[\frac{\omega_{n}^{2}}{p^{2}+2 \zeta \omega_{n}^{2} p+\omega_{n}^{2}}\right] e(t) \\
& \dot{k}_{i}=\left(-\gamma_{i}\right) \varepsilon(t)\left[\frac{\omega_{n}^{2}}{p^{2}+2 \zeta \omega_{n}^{2} p+\omega_{n}^{2}}\right] e(t) \\
& \dot{k}_{d}=\left(\gamma_{d}\right) \varepsilon(t)\left[\frac{\omega_{n}^{2}}{p^{2}+2 \zeta \omega_{n}^{2} p+\omega_{n}^{2}}\right] y(t)
\end{aligned}
$$

where: $\gamma_{p}, \gamma_{i}$ and $\gamma_{d}$ are the adaptation gains.

The expression of the adaptive PID controller is the following:

$$
\begin{aligned}
& u(t)=\left(-\gamma_{p}\right) \varepsilon(t)\left[\frac{\omega_{n}^{2}}{p^{2}+2 \zeta \omega_{n}^{2} p+\omega_{n}^{2}}\right] e(t)-\left(\gamma_{i}\right) \varepsilon(t)\left[\frac{\omega_{n}^{2}}{p^{2}+2 \zeta \omega_{n}^{2} p+\omega_{n}^{2}}\right] e(t) \\
& +\left(\gamma_{d}\right) \varepsilon(t)\left[\frac{\omega_{n}^{2}}{p^{2}+2 \zeta \omega_{n}^{2} p+\omega_{n}^{2}}\right] y(t)
\end{aligned}
$$




\section{SIMULATION RESULTS}

The Simulink diagram of the closed-loop system with the derived adaptive PID controller is shown in Figure 2. The simulation is done in MATLAB/Simulink environment. The closed-loop system is made of the following subsystems:

- Plant model represented as a second order transfer function.

- Reference model.

- Adaptation control algorithms.

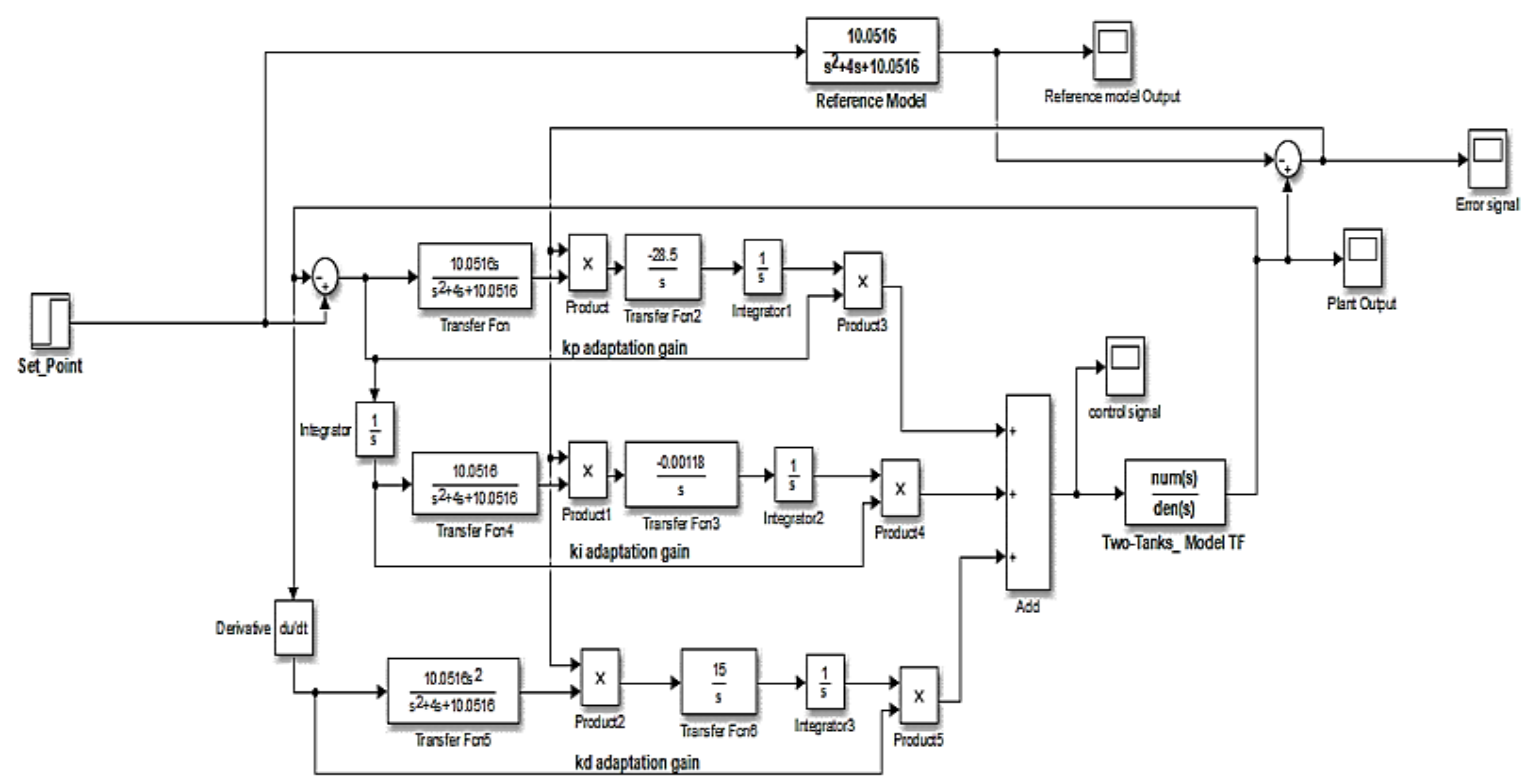

Figure 2. Simulink diagram of the adaptive control algorithm based on the MIT rule

The simulations are done to evaluate the performance of the adaptive scheme under the following parameters:

- The set-points are: $10 \mathrm{~cm}$ and $13 \mathrm{~cm}$.

- The values of the adaptation gains are: $\gamma_{p}=28.5, \gamma_{i}=1.18 \times 10^{-3}$ and $\gamma_{d}=-15$.

- A random disturbance of magnitude 0.8 and frequency 0.1 Hertz occurs at the output of the plant.

- $\quad \beta_{1}$ (valve ratio of the outlet pipe tank 1) and $\beta_{2}$ (valve ratio of the outlet pipe of tank 2) are unknown, but their values are bounded to a range of values.

- $\quad \beta_{1}$ varies within the following interval: [1.22522 1.9895]. The values: $1.3784 ; 1.5315195 ; 1.6081$ and 1.6847 are selected randomly.

- $\quad \beta_{2}$ varies within the following interval: $[0.545603 \quad 0.818405]$. The values: $0.5661 ; 0.6820043 ; 0.6615$ and 0.7502 are randomly selected.

4.1. Case 1: Simulation of the closed-loop adaptive system where there are no variations of the parameters

The simulation shows the following results:

- The graphs of the level of liquid $y$ in Tank 2 .

- $\quad \beta_{1}$ (valve ratio of the outlet pipe tank 1) and $\beta_{2}$ (valve ratio of the outlet pipe of tank 2) are at their original values: $\beta_{1}=1.5315195$ and $\beta_{2}=0.6820043$.

- Simulation results when the set point is $10 \mathrm{~cm}$ as shown in Figure 3.

- Simulation results when the set point is $13 \mathrm{~cm}$ as shown in Figure 4.

The results of the simulations show that the designed model reference adaptive PID-controller has

excellent tracking performance, good rising time and it does not have any overshoot and steady state error. 


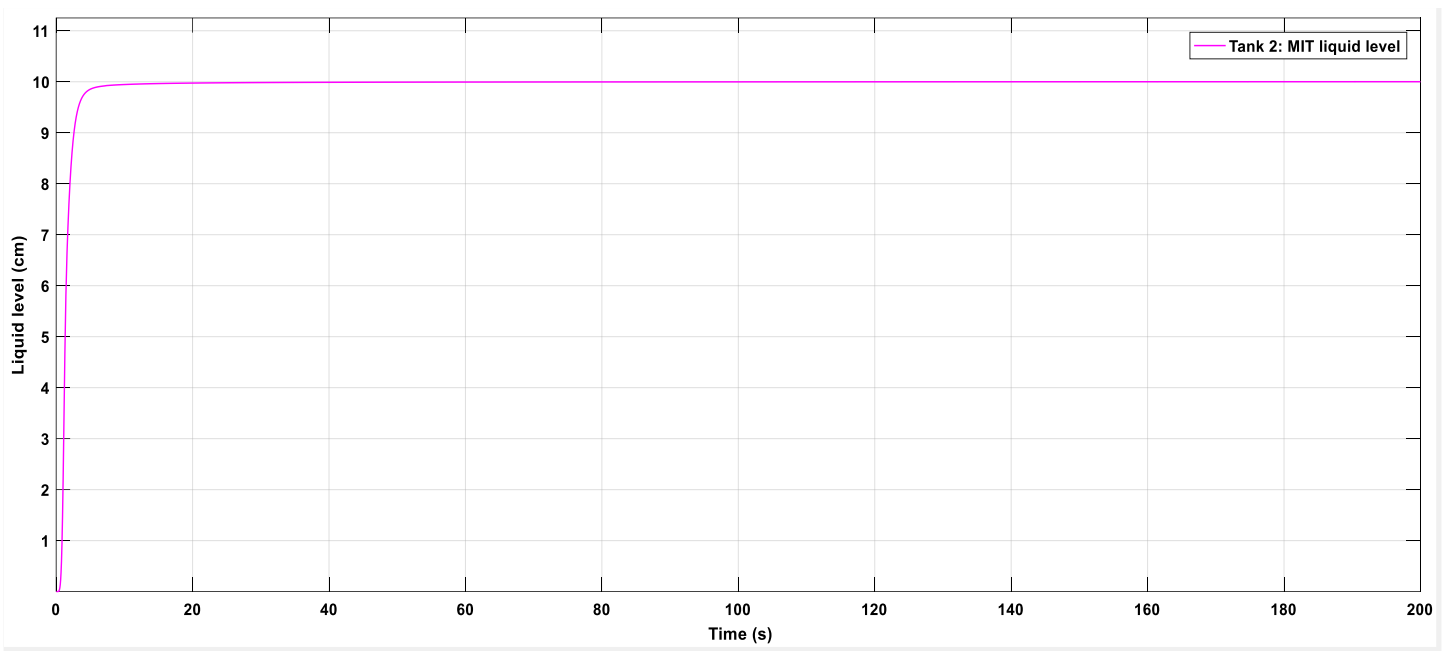

Figure 3. Liquid level when there are no parameters variations; and the set-point is $10 \mathrm{~cm}$

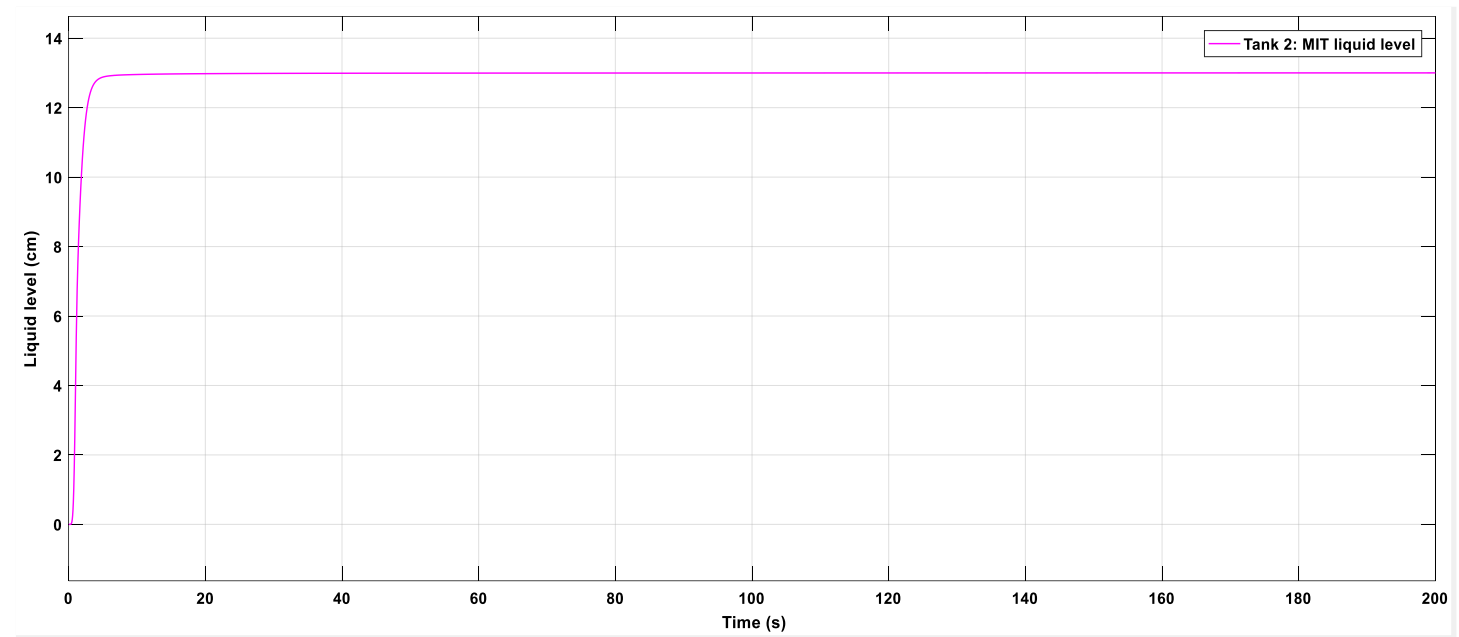

Figure 4. Liquid level when there are no parameters variations; and the set-point is $13 \mathrm{~cm}$

4.2. Case 2: simulation of the closed-loop system when variations of the process parameters occur 4.2.1. Scenario 1

$-\quad \beta_{1}$ and $\beta_{2}$ vary respectively from their original values to the following values: 1.3784 and 0.7502 at $60^{\text {th }}$ second of the simulation time and both values remain unchanged till the end of the simulation.

- A conventional PI controller of parameters $K_{p}=0.001$ and $K_{i}=4$ is designed on MATLAB for the model of the two-tank system.

- The performance of the closed-loop system under normal PI controller is compared to the performance of the closed-loop system under the MRAPIDC controller.

- Simulation results when the set point is $10 \mathrm{~cm}$ as shown in Figure 5

- Simulation results when the set point is $13 \mathrm{~cm}$ as shown in Figure 6

\subsubsection{Scenario 2}

Results when the closed-loop system is subjected to new parameters variations:

- $\beta_{1}$ and $\beta_{2}$ vary respectively from their original values to the following values: 1.6847 and 0.6615 at 90 seconds of the simulation time and both values remain unchanged till the end of the simulation.

- Simulation results when the set point is $10 \mathrm{~cm}$ as shown in Figure 7

- Simulation results when the set point is $13 \mathrm{~cm}$ as shown in Figure 8 


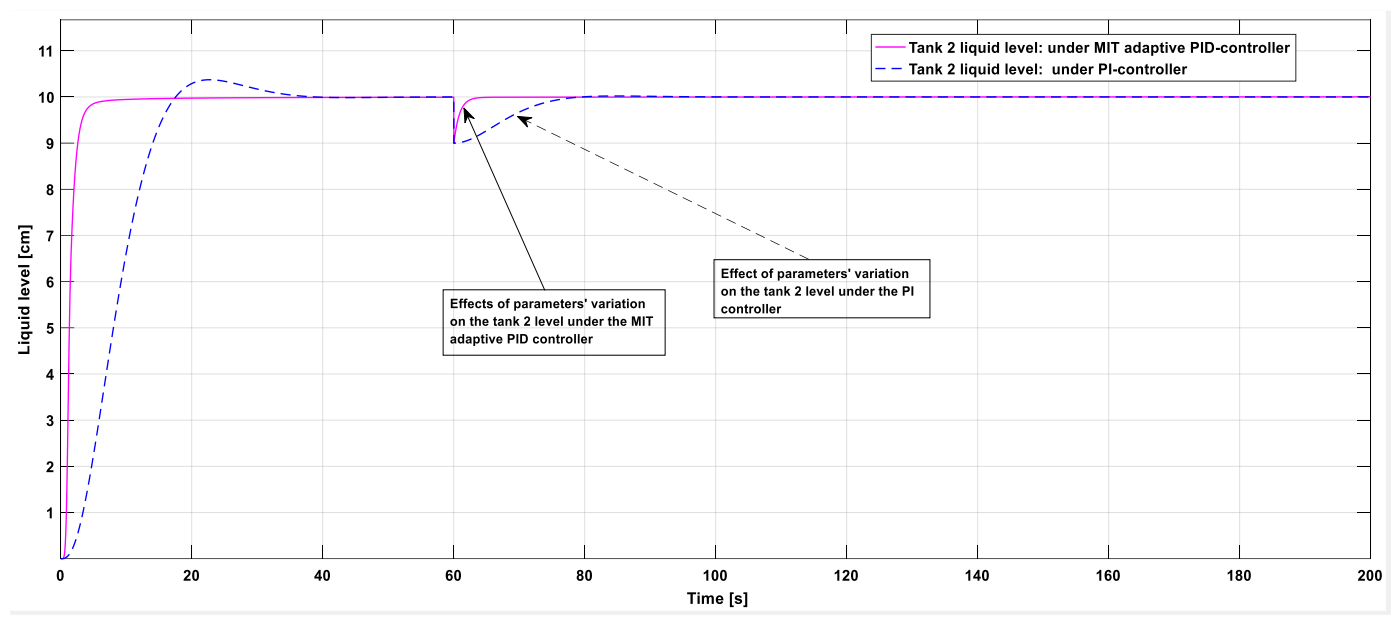

Figure 5. Adaptive controller-based liquid level vs PI-controller based liquid level behaviour when the parameters $\beta_{1}$ and $\beta_{2}$ respectively vary from their original values to: 1.3784 and 0.7502 at the $60^{\text {th }}$ second of the simulation time; and the set-point is $10 \mathrm{~cm}$

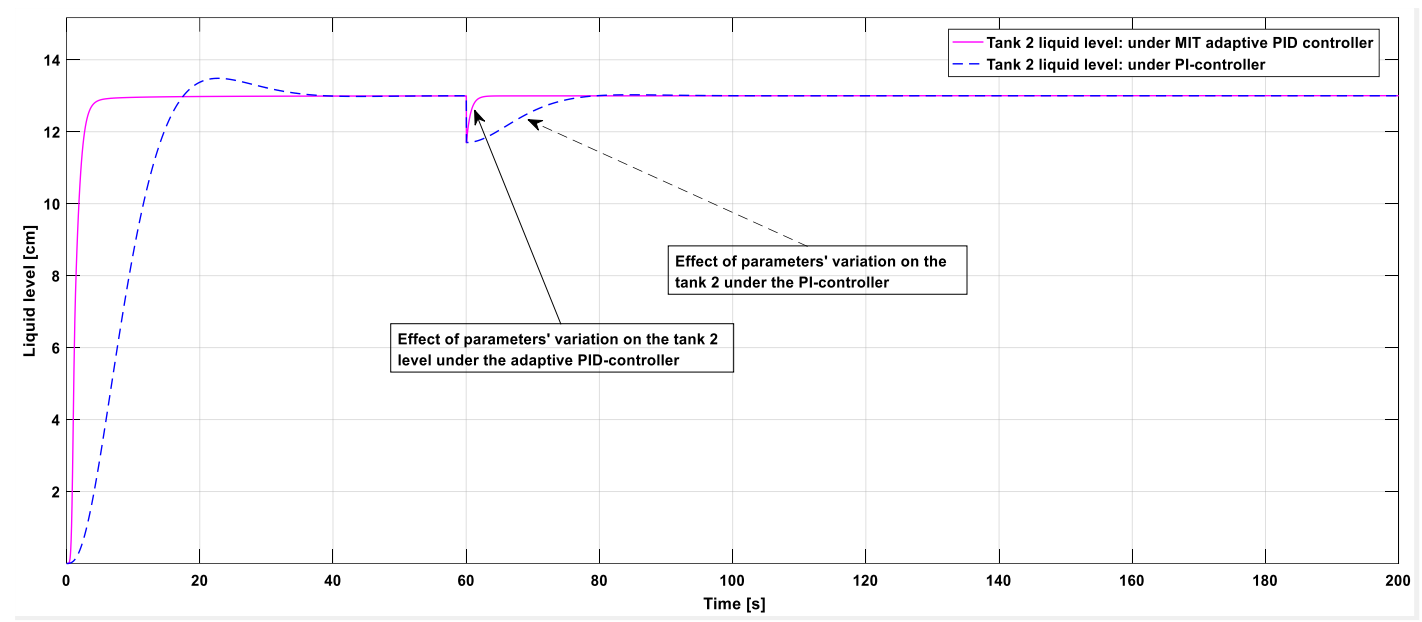

Figure 6. Adaptive controller-based liquid level vs PI-controller based liquid level behaviour when the parameters $\beta_{1}$ and $\beta_{2}$ vary respectively from their original values to: 1.3784 and 0.7502 at the $60^{\text {th }}$ second of the simulation time; and the set-point is $13 \mathrm{~cm}$

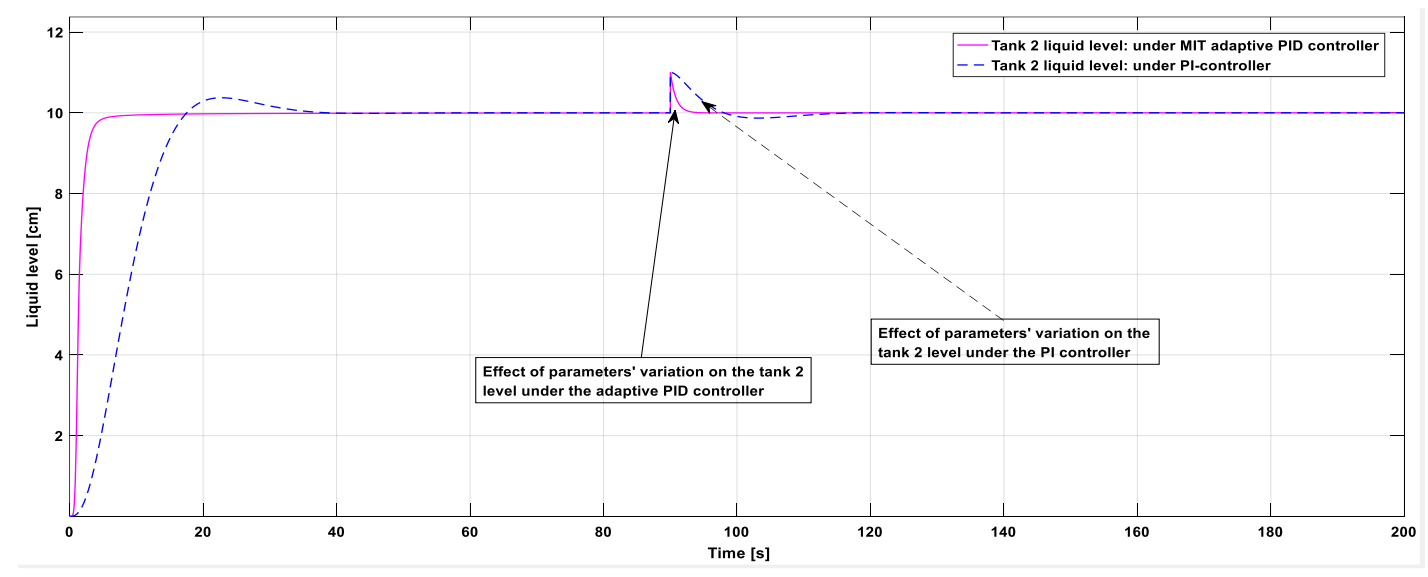

Figure 7. Adaptive controller-based liquid level vs PI-controller based liquid level behaviour when the parameters $\beta_{1}$ and $\beta_{2}$ vary respectively to 1.6847 and 0.6615 at the $90^{\text {th }}$ second of the simulation time; and the set-point is $10 \mathrm{~cm}$ 


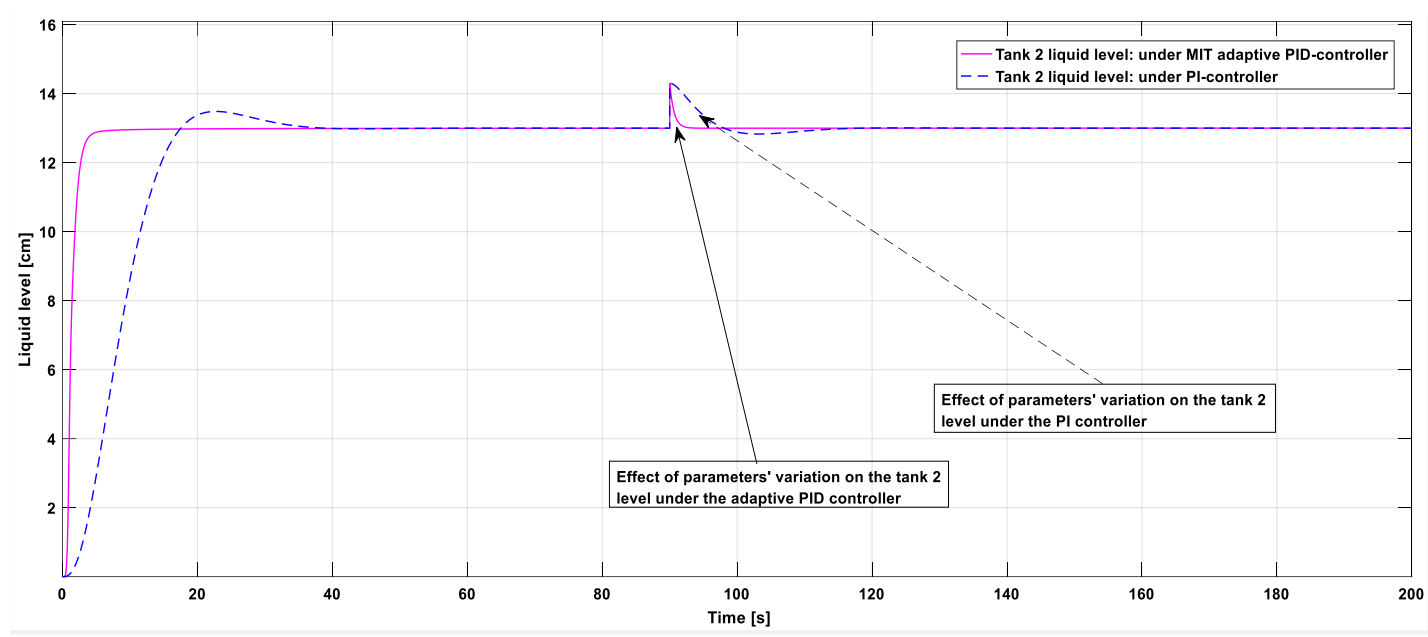

Figure 8. Adaptive controller-based liquid level vs PI-controller based liquid level behaviour when the parameters $\beta_{1}$ and $\beta_{2}$ vary respectively to 1.6847 and 0.6615 at the $90^{\text {th }}$ second of the simulation time; and the set-point is $13 \mathrm{~cm}$

In Table 2, a summary of the performance comparison between the closed-loop system with modelreference Adaptive PID-controller and the closed-loop system with PI controller when the system is affected by variations of the parameters is given. The results of the simulation show that the closed-loop system under adaptive PID controller has better performance than the PI controller. The adaptive PID controller shows stability and robustness with faster rise time and settling time. It also has a quicker recovery time when variation of parameters occurs compared to the PI controller.

Table 2. Summary of the performance comparison between the closed-loop system with model reference adaptive controller and the closed-loop system with PI controller when the two scenarios of case 2 are considered

\begin{tabular}{|c|c|c|c|c|c|}
\hline \multirow[t]{2}{*}{$\begin{array}{c}\text { Set } \\
\text { point }\end{array}$} & \multirow[t]{2}{*}{ Characteristics of the closed-loop system } & \multicolumn{2}{|c|}{$\begin{array}{c}\text { Case 2: Scenario } 1 \\
\beta_{1}=1.3784 \\
\beta_{2}=0.7502\end{array}$} & \multicolumn{2}{|c|}{ 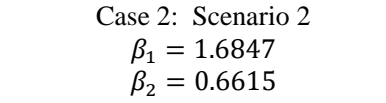 } \\
\hline & & $\begin{array}{l}\text { Adaptive PID } \\
\text { controller }\end{array}$ & PI Controller & $\begin{array}{l}\text { Adaptive PID } \\
\text { Controller }\end{array}$ & PI Controller \\
\hline \multirow[t]{7}{*}{$10 \mathrm{~cm}$} & Time delay & 0 & 0 & 0 & 0 \\
\hline & Overshoot when parameters vary & $-9.8 \%$ & $-10.02 \%$ & $10 \%$ & $+10.01 \%$ \\
\hline & Rising time & 1.95 seconds & 12.02 seconds & 1.95 seconds & 5.75 seconds \\
\hline & $\begin{array}{l}\text { Steady state error before parameters } \\
\text { variations }\end{array}$ & 0 & 0 & 0 & 0 \\
\hline & $\begin{array}{l}\text { Steady state error when parameters } \\
\text { variations occur }\end{array}$ & -0.98 & -1 & 1 & +1.01 \\
\hline & Settling time before parameters variations & 22.4 seconds & 40.51 seconds & 25.03 seconds & 37.2 seconds \\
\hline & $\begin{array}{l}\text { Closed-loop system recovery time after } \\
\text { parameters variations }\end{array}$ & 4.03 seconds & 30.11 seconds & 4.86seconds & 29.31 seconds \\
\hline \multirow[t]{7}{*}{$13 \mathrm{~cm}$} & Time delay & 0 & 0 & 0 & 0 \\
\hline & Overshoot when parameters vary & $-10 \%$ & $-10.03 \%$ & $10 \%$ & $10.02 \%$ \\
\hline & Rising time & 1.99seconds & 9.4seconds & 1.99 seconds & 10.71seconds \\
\hline & $\begin{array}{l}\text { Steady state error before parameters } \\
\text { variations }\end{array}$ & 0 & 0 & 0 & 0 \\
\hline & $\begin{array}{l}\text { Steady state error when parameter variations } \\
\text { occur }\end{array}$ & -1.3 & -1.3 & +1.3 & +1.3 \\
\hline & Settling time before parameters variations & 15.79 seconds & 39.91 seconds & 18.64 seconds & 39.83 seconds \\
\hline & $\begin{array}{l}\text { Closed-loop system recovery time after } \\
\text { parameters variations }\end{array}$ & 3.05 seconds & 24.87 seconds & 3.41 seconds & 29.35 seconds \\
\hline
\end{tabular}

\subsection{Performance comparison of the Pi-controller and the model reference adaptive PID-controller in terms of random input disturbance rejection}

The random disturbance has the following characteristics:

- Amplitude: $0.8 \mathrm{~cm}$ 
- Frequency: 0.1 Hertz

The Simulink block diagram of the closed-loop system with input disturbance is shown in Figure 9.

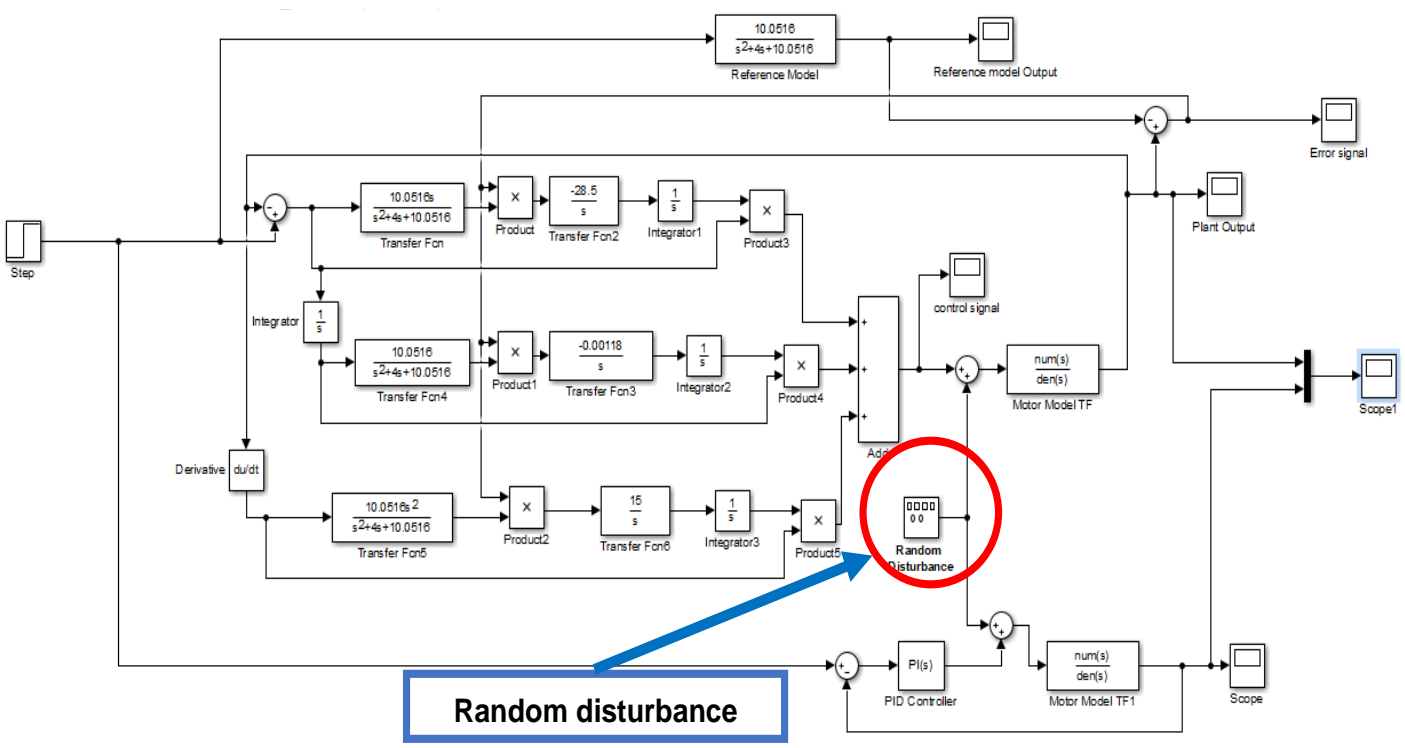

Figure 9. Simulink diagram for the comparison of the performance of the adaptive PID control algorithm and the PI controller-based algorithm when a random disturbance occurs at the input of the plant

4.3.1. Simulation of the closed-loop system when parameters variations and a random input disturbance occur at the $50^{\text {th }}$ seconds of the simulation time

- $\beta_{1}$ and $\beta_{2}$ vary respectively to the following values: 1.6081 and 0.5661 at the 50th second of the simulation time and both values remain unchanged till the end of the simulation.

- The characteristics of the output disturbance at the input of the plant are:

- Amplitude: $1.4 \mathrm{~cm}$

- Frequency: 0.25 Hertz

- Simulation results when the set-point is $10 \mathrm{~cm}$ as shown in Figure 10:

- Simulation results when the set-point is $13 \mathrm{~cm}$ as shown in Figure 11:

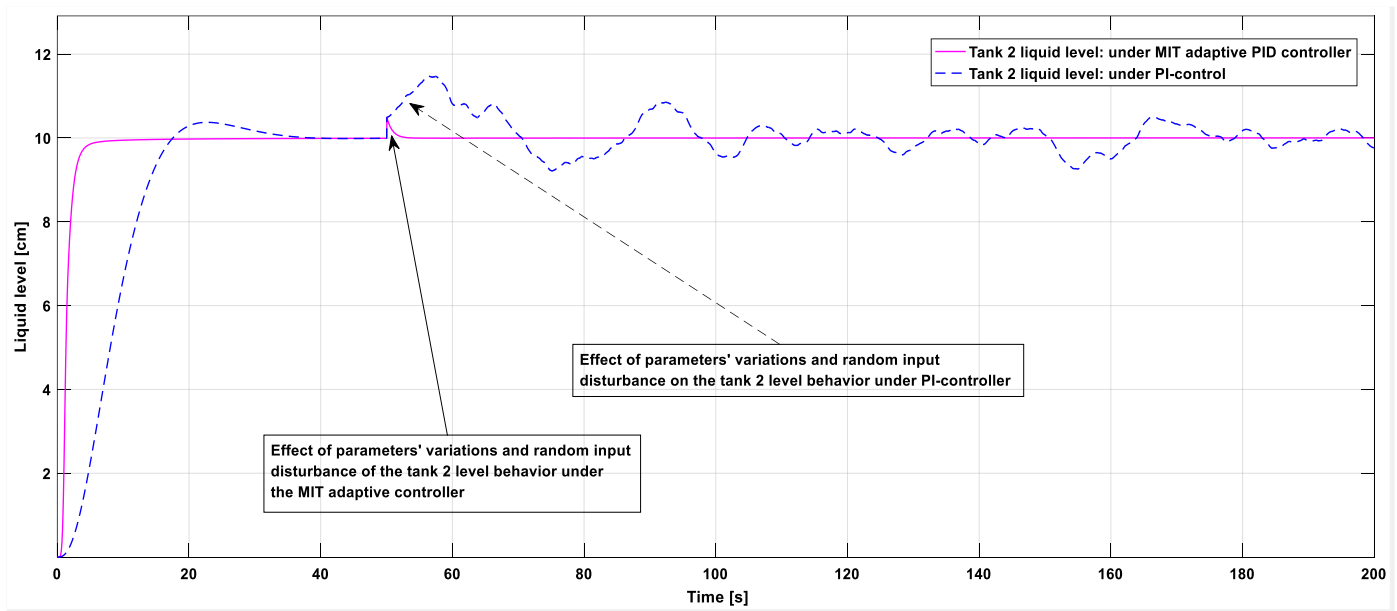

Figure 10. Adaptive controller-based liquid level vs PI-controller based liquid level when at the $50^{\text {th }}$ second of the simulation time; $\beta_{1}$ and $\beta_{2}$ vary respectively from their original values to: 1.6081 and 0.5661 , at the same time a random input disturbance occurs and both remain unchanged till the end of the simulation; the set-point is $10 \mathrm{~cm}$ 


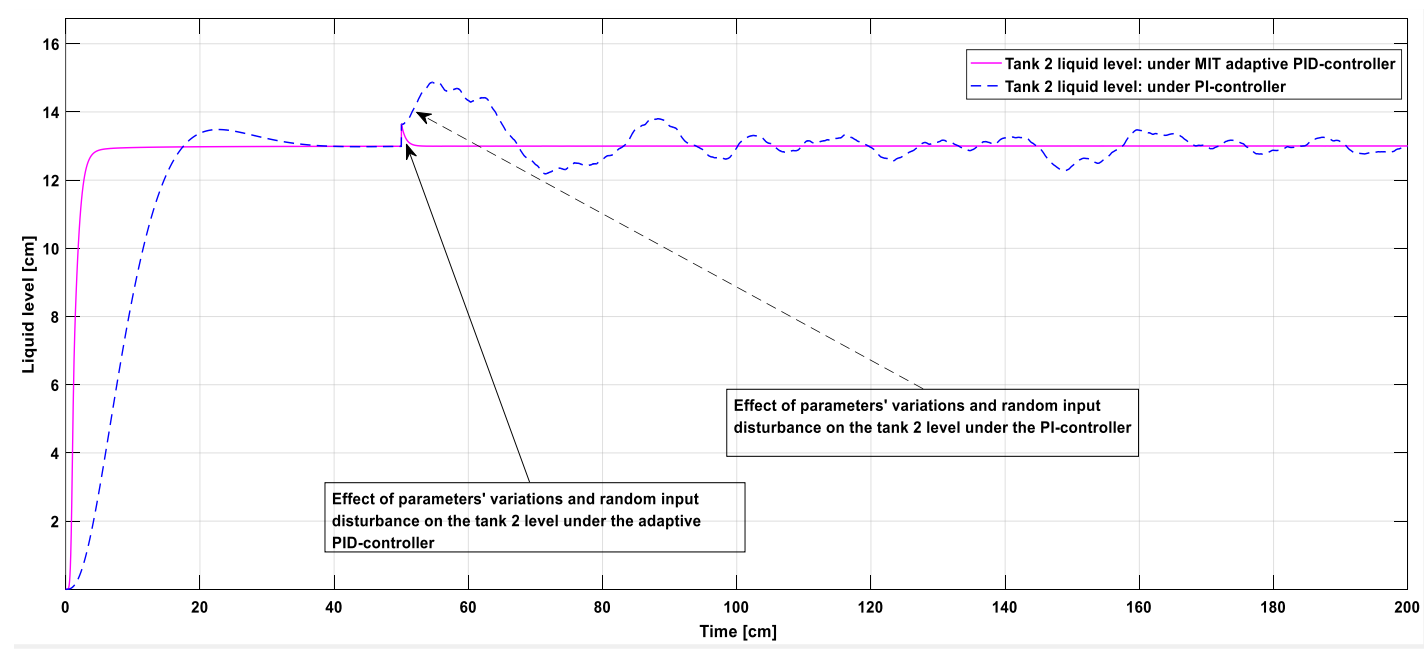

Figure 11. Adaptive controller-based liquid level vs PI-controller based liquid level when at the $50^{\text {th }}$ second of the simulation time; $\beta_{1}$ and $\beta_{2}$ vary respectively from their original values to: 1.6081 and 0.5661 , at the same time a random input disturbance occurs and both remain unchanged till the end of the simulation; the set-point is $13 \mathrm{~cm}$

The results of the simulation show that the adaptive PID controller is robust to parameters' variations and rejects input disturbance, while the conventional PI controller shows an unstable convergence behaviour. The performance of the adaptive PID controller is outstanding.

\subsection{Analysis of the design specification achievement}

In the previous sections, the two-tank liquid level system is subjected to parameters' variation and random input disturbances, both are applied to the closed-loop system in different conditions.

The various simulations of the two-tank liquid level process reveal the following observations:

- The adaptive PID controller and the system adapt to the changes of plant parameters.

- The adaptive PID controller and the system reject random input disturbances.

- The stability of the system is achieved.

- The error signals go to zero.

- The plant output always follows the reference model and the set-points trajectories regardless of the bounded values of the varying parameters, and the introduction of random input disturbances.

\section{CONCLUSION}

In this paper, the first contribution is the design and derivation of the Adaptive PID controller based on the MIT approach. Then, the performances of a standard PI controller designed on MATLAB and a new model reference adaptive PID controller designed based on MIT technique are compared for a two-tank process subjected to parameters variations and disturbances. The model reference adaptive PID controller can stabilize the closed-loop system when variations of parameters occur at a speed eight times faster than the conventional PI controller, which is a significant improvement.

The designed model reference adaptive PID controller showed outstanding performances and is recommended as control method to be used for the stabilization of the closed-loop system subjected to internal parameters variations and external random disturbances. For future research, the algorithm can be improved to implement multiple model reference methodologies in real-time to push the boundaries of the control algorithm.

\section{REFERENCES}

[1] J. Slotine, "Applied Nonlinear Control," Prentice Hall, New Jersey, 1991.

[2] S. Coman, "Model Reference Adaptive Control for a Dc Electrical Drive," Bulletin of the Transilvania University of Brasov. Engineering Sciences. Series, vol. 6, no. 2, 2013.

[3] M. A Fellani and A. M. Gabaj, "PID Controller Design for Two Tanks Liquid Level Control System Using Matlab," International Journal of Electrical and Computer Engineering (IJECE), vol. 3, no. 3, pp. 436-442, 2015. 
[4] P. Swarnkar, et al., "Effect of Adaptation Gain in Model Reference Adaptive Controlled Second Order System," Engineering, Technology \& Applied Science Research, vol. 1, no. 3, pp. 70-75 2011.

[5] J. Vojtesek, et al., "Simulation of 1DOF and 2DOF adaptive control of the water tank model," Proceedings - 29th European Conference on Modelling and Simulation (ECMS), 2015.

[6] M. Navabi and H. Mirzaei, "Robust Optimal Adaptive Trajectory Tracking Control of Quadrotor Helicopter," Latin American Journal Solids and Structures, vol. 14, pp. 1040-1063, 2017.

[7] G. Nandhinipriyanka, et al., "Design of model reference adaptive controller for cylinder tank system," International Journal of Pure and Applied Mathematics, vol. 118, no. 20, 2018.

[8] M. S. Minhat, et al., "Adaptive control method for core power control in TRIGA Mark II reactor," IOP Conference Series: Materials Science and Engineering, 2018.

[9] M. H. A. Jalil, et al., "Model Reference Adaptive Controller without Integral (MRACWI) for Position Control of a DC Motor," Applications of modelling and simulation, vol. 3, pp. 18-27, 2019.

[10] A. N. K. Nasir, et al., "Performance comparison between sliding mode control (SMC) and PD-PID controllers for a nonlinear inverted pendulum system," World Academy of Science, Engineering and Technology, vol. 71, pp. 400-405, 2010.

[11] A. Soltan, et al., "Fractional order PID system for supressing epileptic activities," IEEE International Conference on Applied System Invention (ICASI), pp. 338-341, 2018.

[12] M. A. Ahmad and R. R. Ismail, "A data-driven sigmoid-based PI controller for buck-converter powered DC motor," IEEE Synposium on Computer Applications and Industrial Electronics (ISCAIE), pp. 81-86, 2017.

[13] H. Senberber and A. Bagis, "Fractional PID controller design for fractional order systems using ABC algorithm," IEEE Electronics, pp. 1-7, 2017.

[14] M. R. B. Ghazali, et al., "Adaptive safe experimentation dynamics for data-driven neuroendocrine-PID control of MIMO systems," IETE Journal of Research, pp. 1-14, 2019.

[15] Y. D. Mfoumboulou and R. Tzoneva, "Development of a Model Reference Digital Adaptive Control Algorithm for a Linearized Model of a Nonlinear Process," International Journal of Applied Engineering Research, vol. 13, no. 23, pp. 16662-16675, 2018.

[16] N. Winston, et al., "Design and performance comparison of different adaptive control schemes for pitch angle control in a twin-rotor MIMO system," International Journal of Electrical and Computer Engineering (IJECE), vol. 9, no. 5, pp. 4114-4129, 2019.

[17] K. J. Astrom and B. Wittenmark, “Adaptive Control," Second Edition, Dover Publications, 2008.

[18] N. Nise, "Control Systems Engineering Eighth Edition," John Wiley \& Sons, Limited, 2019.

[19] K. Ogata, "Modern Control Engineering Fourth Edition," Upper Saddle River, New Jersey, Prentice Hall, 2002.

[20] Y. D Mfoumboulou, "Development of nonlinear control algorithms for implementation in distributed system," Master Thesis, Cape Peninsula University of Technology, 2014.

[21] MathWorks, "Control System toolbox user's guide 2016a," The MathWorks, Inc., 2016.

[22] A.B. Campo, "PID Control Design," MATLAB - A Fundamental Tool for Scientific Computing and Engineering Applications, vol. 1, pp. 3-18, 2012.

[23] S. Coman and C. Boldisor, "Adaptive Pi Controller Design to Control a Mass - Damper - Spring Process," Bulletin of the Transilvania University of Brasov, vol. 7, no. 2, 2014.

[24] T. Basten, et al., "Model-Based Design of Adaptive Embedded Systems," Model-based design of adaptive embedded systems. Verlag London: Springer, vol. 22, 2013.

[25] E. Kurniawan, et al., "Model-Based Control for Tracking and Rejection of Periodic Signals," 7th International Conference on Information Technology and Electrical Engineering (ICITEE), pp. 548-552, 2015.

\section{BIOGRAPHY OF AUTHOR}

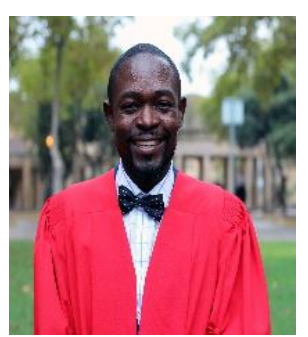

Dr. Yohan Darcy Mfoumboulou is a post doctorate fellow at Cape Peninsula University of Technology (CPUT). His research interests are in the fields of Classical and Modern Control, Advanced Nonlinear Control, Real-Time Distributed Control Systems, Linear and Nonlinear Adaptive Networked Control, Digital Adaptive Control and Process Control and Instrumentation. 